\title{
Two-year outcome after biodegradable polymer sirolimus- and biolimus-eluting coronary stents (from the randomised SORT OUT VII trial)
}

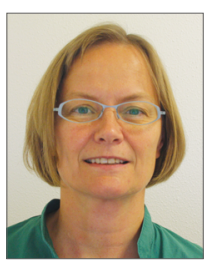

Lisette Okkels Jensen ${ }^{1 *}$, MD, DMSci, PhD; Michael Maeng ${ }^{2}, \mathrm{MD}, \mathrm{PhD}$;

Bent Raungaard ${ }^{3}, \mathrm{MD}, \mathrm{PhD}$; Knud Nørregaard Hansen ${ }^{1}, \mathrm{MD}$; Johnny Kahlert ${ }^{4}, \mathrm{MSc}$;

Svend Eggert Jensen 3 , MD, PhD; Henrik Steen Hansen ${ }^{1}$, MD, DMSci;

Jens Flensted Lassen², MD, PhD; Hans Erik Bøtker², MD, DMSci, PhD;

Evald Høj Christiansen ${ }^{2}, \mathrm{MD}, \mathrm{PhD}$

1. Department of Cardiology, Odense University Hospital, Odense, Denmark; 2. Department of Cardiology, Aarhus University Hospital, Aarhus, Denmark; 3. Department of Cardiology, Aalborg University Hospital, Aalborg, Denmark; 4. Department of Clinical Epidemiology, Aarhus University Hospital, Aarhus, Denmark

\section{Introduction}

The persistence of polymer material on first- and second-generation coronary drug-eluting stents after completion of drug release has been suggested as a trigger for a chronic inflammatory response ${ }^{1}$. Coronary drug-eluting stents with biodegradable polymers have been designed to overcome concerns over the delayed arterial healing, which might increase the risk of very late stent thrombosis and restenosis. The "Randomized Comparison of a Biodegradable Polymer Ultrathin Strut Sirolimus-Eluting Stent With a Biodegradable Polymer Biolimus-Eluting Stent in Patients Treated With Percutaneous Coronary Intervention: The SORT OUT VII Trial"'2 demonstrated excellent one-year results with low target lesion failure rates. The present study extends the follow-up to two years.

\section{Methods}

\section{OUTCOME MEASURES}

The primary endpoint of target lesion failure is a composite of cardiac death, myocardial infarction (not related to other than index lesion) or clinically indicated target lesion revascularisation with percutaneous coronary intervention or coronary artery bypass operation within 24 months. The secondary endpoints were defined in the primary publication ${ }^{2}$.

\section{STATISTICAL ANALYSIS}

In analyses of every endpoint, follow-up continued until the date of an endpoint event, death, emigration, or 24 months after stent implantation, whichever came first. We constructed survival curves based on time to events, accounting for the competing risk of death (in cases of death not included in the outcome). Rate ratios (RR) were calculated for target lesion failure at 24-month follow-up. Rate ratios were calculated by modified Poisson regression analysis with a sandwich error estimation to assess whether difference detected at baseline had any effect on the result.

\section{Results}

A total of 2,525 patients were randomly assigned to receive either the biodegradable polymer sirolimus-eluting Orsiro stent

*Corresponding author: Odense University Hospital, Department of Cardiology, Sdr. Boulevard 29, 5000 Odense C, Denmark. E-mail: okkels@dadlnet.dk 
(Biotronik, Bülach, Switzerland) or the biodegradable polymer biolimus-eluting Nobori ${ }^{\circledR}$ stent (Terumo Corp., Tokyo, Japan). Three patients were lost to follow-up (on days 6, 81 and 610) because of emigration. Complete follow-up data were available for 2,523 (99.9\%) patients.

At two years, the composite endpoint target lesion failure had occurred in 84 patients $(6.7 \%)$ in the biodegradable polymer sirolimus-eluting Orsiro group and in 89 patients $(7.0 \%)$ in the biodegradable polymer biolimus-eluting Nobori group (RR 0.94, 95\% CI: 0.70-1.28) (Figure 1, Table 1). Rates of death, cardiac death, myocardial infarction, and clinically driven target lesion revascularisation at two years did not differ significantly between the two stent groups. Adjusting for age and reference vessel diameter did not change the risk ratio significantly. At two years, the rate of definite stent thrombosis was numerically lower in the sirolimus-eluting Orsiro group (10 patients [0.8\%] versus 18 patients $[1.4 \%]$ in the biolimus-eluting Nobori group [RR 0.56, 95\% CI: 0.26-1.21]). This reduced rate of definite stent thrombosis in the biodegradable polymer sirolimuseluting stent was attributable to a lower risk of early definite stent thrombosis (Table 1). In contrast, the rate of very late stent thrombosis did not differ significantly between the two groups. Findings for the primary endpoint target lesion failure were consistent across pre-specified stratified analyses except for patients with multivessel disease and patients treated with more than one stent (Figure 2).
Table 1. Clinical outcomes.

\begin{tabular}{|l|c|c|c|c|}
\hline \multicolumn{1}{|c|}{ Events at 2 years } & $\begin{array}{c}\text { Orsiro stent } \\
\text { (N=1,261) } \\
\mathbf{n ( \% )}\end{array}$ & $\begin{array}{c}\text { Nobori stent } \\
\text { (N=1,264) } \\
\mathbf{n}(\%)\end{array}$ & $\begin{array}{c}\text { Rate ratio } \\
\text { (95\% confidence } \\
\text { interval) }\end{array}$ & p-value \\
\hline Target lesion failure & $84(6.7)$ & $89(7.0)$ & $0.94(0.70-1.28)$ & 0.71 \\
\hline All-cause mortality & $60(4.8)$ & $45(3.6)$ & $1.35(0.91-1.99)$ & 0.13 \\
\hline Cardiac death & $29(2.3)$ & $24(1.9)$ & $1.22(0.71-2.10)$ & 0.47 \\
\hline Non-cardiac death & $31(2.5)$ & $21(1.7)$ & $1.49(0.86-2.60)$ & 0.16 \\
\hline Myocardial infarction & $46(3.6)$ & $47(3.7)$ & $0.98(0.65-1.48)$ & 0.93 \\
\hline $\begin{array}{l}\text { Myocardial infarction not } \\
\text { related to other lesion }\end{array}$ & $29(2.3)$ & $32(2.5)$ & $0.91(0.55-1.51)$ & 0.71 \\
\hline $\begin{array}{l}\text { Target lesion } \\
\text { revascularisation }\end{array}$ & $46(3.6)$ & $57(4.5)$ & $0.81(0.55-1.20)$ & 0.29 \\
\hline $\begin{array}{l}\text { Target vessel } \\
\text { revascularisation }\end{array}$ & $79(6.3)$ & $94(7.4)$ & $0.84(0.62-1.14)$ & 0.26 \\
\hline Stent thrombosis & $10(0.8)$ & $18(1.4)$ & $0.56(0.26-1.21)$ & 0.14 \\
\hline Definite & $1(0.1)$ & $2(0.2)$ & $0.50(0.05-5.52)$ & 0.57 \\
\hline \multicolumn{1}{|c|}{ Acute (<24 hrs) } & $1(0.1)$ & $8(0.6)$ & $0.12(0.02-1.00)$ & 0.05 \\
\hline $\begin{array}{l}\text { Subacute } \\
\text { (24 hrs-30 days) }\end{array}$ & $3(0.2)$ & $5(0.6)$ & $0.60(0.14-2.52)$ & 0.48 \\
\hline Late (>30 days) & $5(0.4)$ & $15(1.2)$ & $0.33(0.12-0.92)$ & 0.03 \\
\hline Within 1 year & $5(0.4)$ & $3(0.2)$ & $1.68(0.40-7.03)$ & 0.48 \\
\hline Very late & $6(0.5)$ & $5(0.4)$ & $1.21(0.37-3.97)$ & 0.76 \\
\hline Probable & $16(1.3)$ & $23(1.8)$ & $0.70(0.37-1.33)$ & 0.27 \\
\hline Definite or probable & $7(0.6)$ & $1.01(0.35-2.88)$ & 0.99 \\
\hline Possible & $29(2.3)$ & $0.80(0.46-1.38)$ & 0.42 \\
\hline $\begin{array}{l}\text { Definite, probable, or } \\
\text { possible }\end{array}$ & $23.8)$ & & & \\
\hline
\end{tabular}
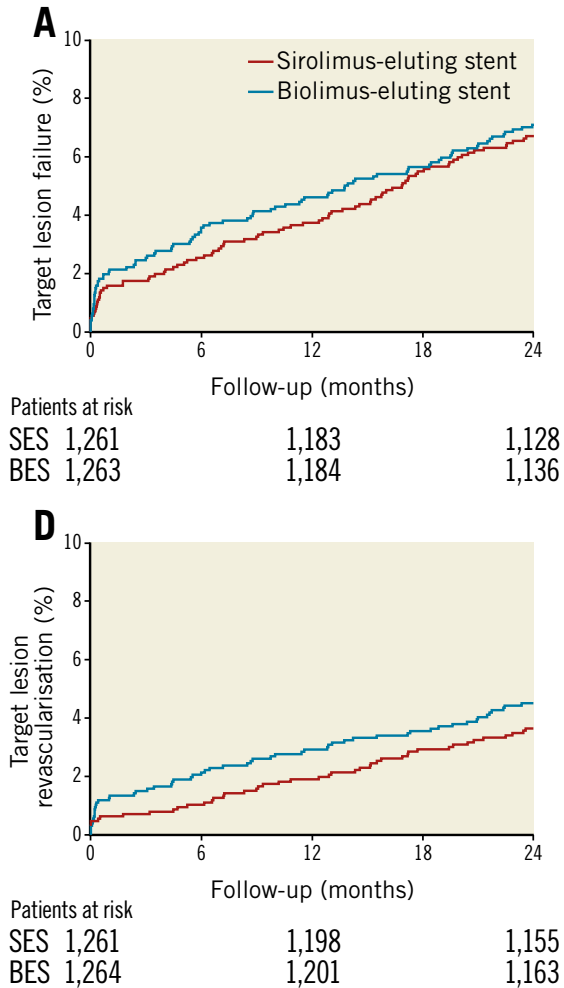

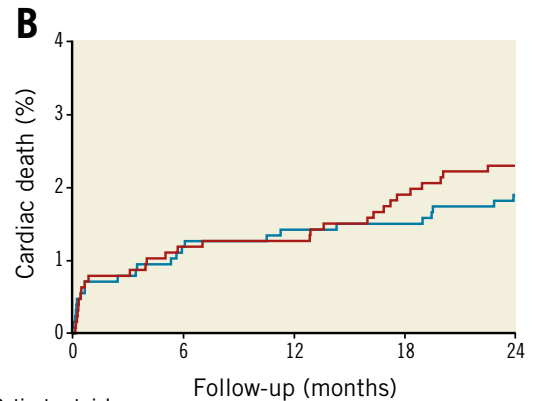

Patients at risk

SES 1,261

BES 1,264

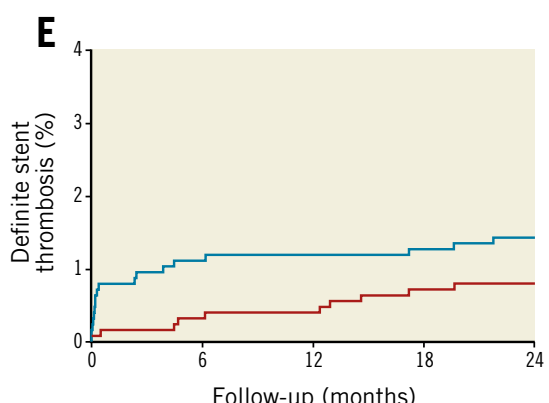

Patients at risk

SES 1,261
BES 1,264
Follow-up (months)

1,217

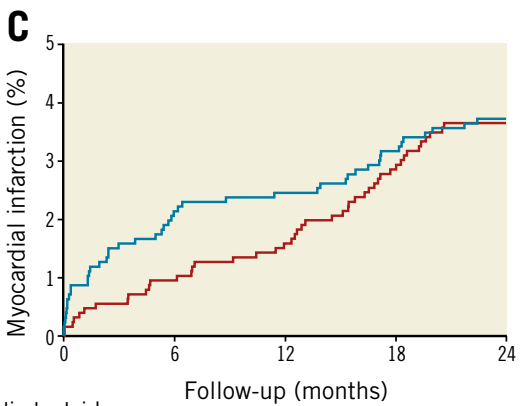

Patients at risk

1,200 SES 1,261

1,217 BES 1,263

1,202

1,206

1,159

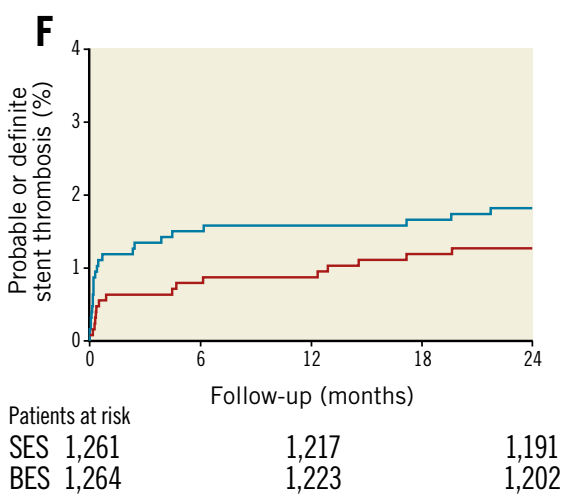

Figure 1. Time-to-event curves for major adverse cardiac events. A) Target lesion failure. B) Cardiac death. C) Myocardial infarction. D) Target lesion revascularisation. E) Definite stent thrombosis. F) Probable or definite stent thrombosis. 


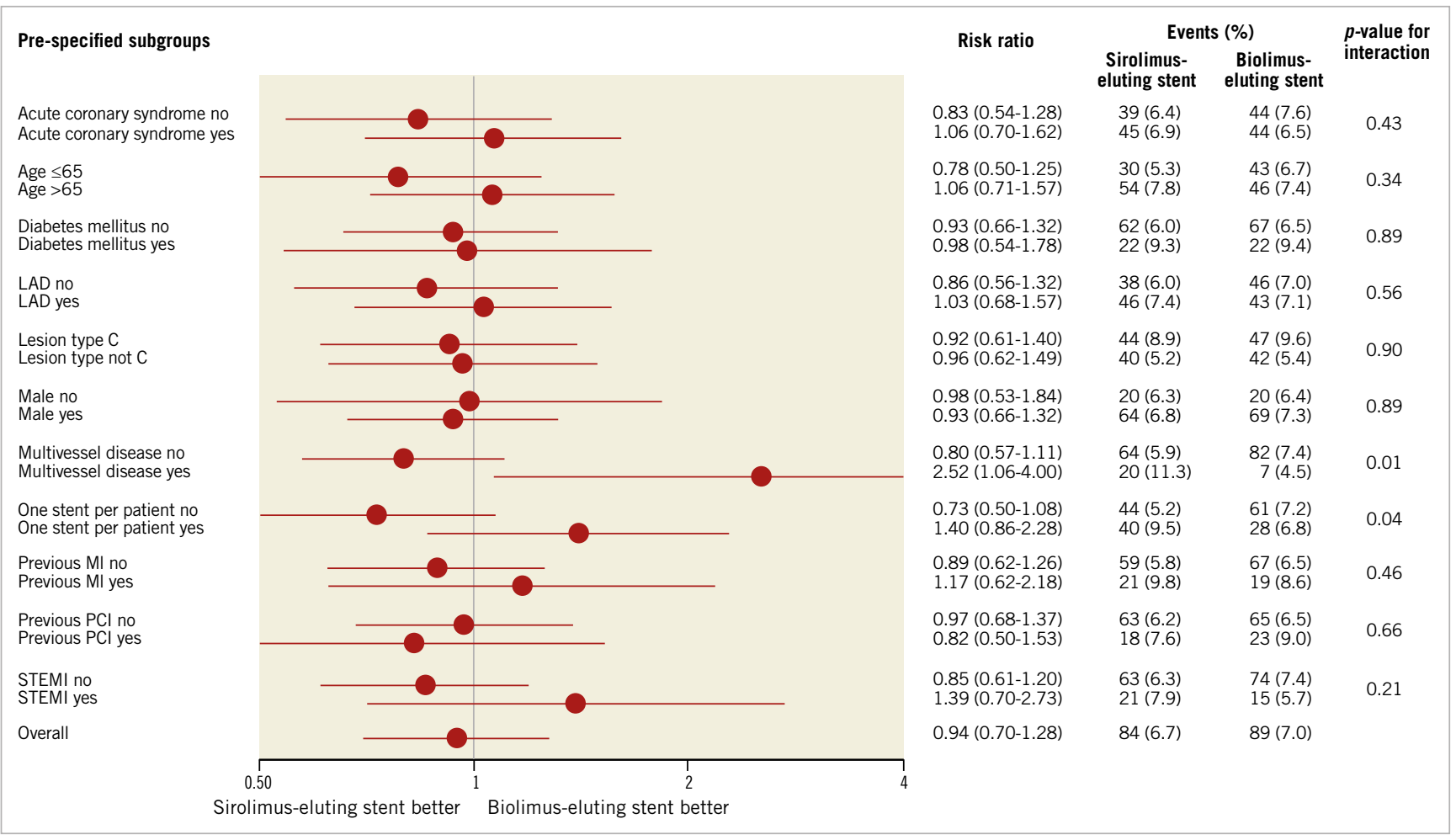

Figure 2. Pre-specified subgroup analysis for the primary endpoint at two-year follow-up

\section{Discussion}

At one-year follow-up we documented non-inferiority of the sirolimus-eluting Orsiro stent and, across a variety of patient and lesion subgroups, the two treatments yielded a similar target lesion failure rate. This result was maintained at two years for the primary endpoint. Within the first year, the rate of definite stent thrombosis was lower in the sirolimus-eluting Orsiro stent group, which was attributable to a lower risk of stent thrombosis within 30 days. At two years, the number of instances of definite stent thrombosis was twice as high in the biolimus-eluting Nobori stent; however, the risk of very late stent thrombosis was similar in the two groups. This is in accordance with several other clinical trials, where the biolimus-eluting Nobori stent has been associated with an increased risk of early stent thrombosis, whereas the risk of very late definite stent thrombosis has been similar between the biolimus-eluting Nobori and the comparator stent $t^{3-5}$. The differences seemed to occur mainly during the first month and we cannot exclude that 1) slower drug release (12 weeks versus approximately 4 weeks), 2) slower polymer degradation (12-24 months compared to 6-9 months), 3) absence of a non-degradable parylene coating between the stent and the biodegradable polymer (as covering the entire Nobori stent), or 4) thinner stent struts $(60-80 \mu \mathrm{m}$ compared to the $120 \mu \mathrm{m})$, might be causal factors in reducing the inflammatory response and the risk of early stent thrombosis. In the "Ultrathin strut biodegradable polymer sirolimus-eluting stent versus durable polymer everolimus-eluting stent for percutaneous coronary revascularisation (BIOSCIENCE)" trial, the biodegradable polymer sirolimus-eluting Orsiro was non-inferior to the durable fluoropolymer everolimus-eluting stent for target lesion failure at one year; no significant differences were noted in stent thrombosis. Comparable safety and efficacy profiles of the two stents were maintained throughout two years of follow-up ${ }^{6}$.

\section{Limitations}

The polymer degradation of the sirolimus-eluting Orsiro stent takes place after 12-24 months. Longer follow-up may show the influence of this polymer degradation.

\section{Conclusions}

Target lesion failure and the risk of very late definite stent thrombosis were similar for the biodegradable polymer sirolimus-eluting Orsiro stent and the biolimus-eluting Nobori stent in unselected patients at two years.

\section{Impact on daily practice}

In biodegradable polymer stents, the timing of polymer biodegradation and strut thickness may affect both vessel wall inflammation and late adverse outcomes following drug-eluting stent implantation. In an all-comer patient population, two-year target lesion failure was similar for the sirolimus-eluting Orsiro stent and the biolimus-eluting Nobori stent. 


\section{Funding}

This study was an investigator-initiated study and supported with equal unrestricted grants from Biotronik (Bülach, Switzerland), and Terumo (Tokyo, Japan). These companies did not have a role in study design, data collection, data analysis, or interpretation of results. Also, they did not have access to the clinical trial database or an opportunity to review the manuscript. The corresponding author had full access to all the data in the study and final responsibility to submit for publication.

\section{Conflict of interest statement}

L.O. Jensen has received research grants from Terumo, Biotronik, St. Jude Medical, and Biosensors to her institution. M. Maeng has received research grants from Boston Scientific, Biosensors International, and Volcano to his institution. The other authors have no conflicts of interest to declare.

\section{References}

1. Finn AV, Nakazawa G, Joner M, Kolodgie FD, Mont EK, Gold HK, Virmani R. Vascular responses to drug eluting stents: importance of delayed healing. Arterioscler Thromb Vasc Biol. 2007;27:1500-10.

2. Jensen LO, Thayssen P, Maeng M, Ravkilde J, Krusell LR, Raungaard B, Junker A, Terkelsen CJ, Veien KT, Villadsen AB, Kaltoft A, Tilsted HH, Hansen KN, Aaroe J, Kristensen SD, Hansen HS, Jensen SE, Madsen M, Botker HE, Berencsi K, Lassen JF, Christiansen EH. Randomized Comparison of a Biodegradable Polymer Ultrathin Strut Sirolimus-Eluting Stent With a Biodegradable Polymer Biolimus-Eluting Stent in Patients Treated With Percutaneous Coronary Intervention: The SORT OUT VII Trial. Circ Cardiovasc Interv. 2016;9(7).
3. Lee JY, Park DW, Kim YH, Ahn JM, Kim WJ, Kang SJ, Lee SW, Lee CW, Park SW, Yun SC, Yang TH, Lee BK, Lee NH, Yang JY, Shin WY, Park HS, Kim KS, Hur SH, Lee SY, Park JS, Choi YS, Lee SU, Her SH, Park SJ. Comparison of biolimus A9-eluting (Nobori) and everolimus-eluting (Promus Element) stents in patients with de novo native long coronary artery lesions: a randomized Long Drug-Eluting Stent V trial. Circ Cardiovasc Interv. 2014; 7:322-9.

4. Smits PC, Hofma S, Togni M, Vazquez N, Valdes M, Voudris V, Slagboom T, Goy JJ, Vuillomenet A, Serra A, Nouche RT, den Heijer P, van der Ent M. Abluminal biodegradable polymer biolimus-eluting stent versus durable polymer everolimus-eluting stent (COMPARE II): a randomised, controlled, non-inferiority trial. Lancet. 2013;381:651-60.

5. Christiansen EH, Jensen LO, Thayssen P, Tilsted HH, Krusell LR, Hansen KN, Kaltoft A, Maeng M, Kristensen SD, Botker HE, Terkelsen CJ, Villadsen AB, Ravkilde J, Aaroe J, Madsen M, Thuesen L, Lassen JF; Scandinavian Organization for Randomized Trials with Clinical Outcome (SORT OUT) V investigators. Biolimus-eluting biodegradable polymer-coated stent versus durable polymer-coated sirolimus-eluting stent in unselected patients receiving percutaneous coronary intervention (SORT OUT V): a randomised non-inferiority trial. Lancet. 2013; 381:661-9.

6. Zbinden R, Piccolo R, Heg D, Roffi M, Kurz DJ, Muller O, Vuilliomenet A, Cook S, Weilenmann D, Kaiser C, Jamshidi P, Franzone A, Eberli F, Juni P, Windecker S, Pilgrim T. Ultrathin Strut Biodegradable Polymer Sirolimus-Eluting Stent Versus Durable-Polymer Everolimus-Eluting Stent for Percutaneous Coronary Revascularization: 2-Year Results of the BIOSCIENCE Trial. J Am Heart Assoc. 2016;5:e03255. 